\title{
The Heat Stress Transcription Factor LlHsfA4 Enhanced Basic Thermotolerance through Regulating ROS Metabolism in Lilies (Lilium Longiflorum)
}

\author{
Chengpeng Wang ${ }^{1,2,+}{ }^{\dagger}$, Yunzhuan Zhou ${ }^{1,+}{ }^{+}, X_{i}$ Yang $^{1}$, Bing Zhang ${ }^{1}$, Fuxiang Xu ${ }^{1}$, Yue Wang ${ }^{1}$, Cunxu Song ${ }^{1}$, \\ Mingfang $\mathrm{Yi}^{1}{ }^{1}$, Nan Ma ${ }^{1}$, Xiaofeng Zhou ${ }^{1, *}$ and Junna He ${ }^{1, *}$
}

1 Beijing Key Laboratory of Development and Quality Control of Ornamental Crops, College of Horticulture, China Agricultural University, Beijing 100193, China; cpwang@cau.edu.cn (C.W.); yunzhuanzhou@cau.edu.cn (Y.Z.); yangxi1994@hotmail.com (X.Y.); zhangbing0405@163.com (B.Z.); xufuxiang@cau.edu.cn (F.X.); wangyue10@cau.edu.cn (Y.W.); S20193172475@cau.edu.cn (C.S.); ymfang@cau.edu.cn (M.Y.); ma_nan@cau.edu.cn (N.M.)

2 Key Laboratory of East China Urban Agriculture, Ministry of Agriculture and Rural Affairs, Institute of Leisure Agriculture, Shandong Academy of Agricultural Sciences, Jinan 250100, China

* Correspondence: zhouxiaofeng@cau.edu.cn (X.Z.); hejunna@cau.edu.cn (J.H.); Tel.: +86-010-62733603 (J.H.)

+ These authors contributed equally to this work.

\section{check for} updates

Citation: Wang, C.; Zhou, Y.; Yang, X.; Zhang, B.; Xu, F.; Wang, Y.; Song, C.; Yi, M.; Ma, N.; Zhou, X.; et al. The Heat Stress Transcription Factor LlHsfA4 Enhanced Basic

Thermotolerance through Regulating ROS Metabolism in Lilies (Lilium Longiflorum). Int. J. Mol. Sci. 2022, 23, 572. https://doi.org/10.3390/ijms 23010572

Academic Editor: Domenica Nigro

Received: 11 November 2021

Accepted: 30 December 2021

Published: 5 January 2022

Publisher's Note: MDPI stays neutral with regard to jurisdictional claims in published maps and institutional affiliations.

Copyright: (C) 2022 by the authors. Licensee MDPI, Basel, Switzerland. This article is an open access article distributed under the terms and conditions of the Creative Commons Attribution (CC BY) license (https:// creativecommons.org/licenses/by/ $4.0 /)$.

\begin{abstract}
Heat stress severely affects the annual agricultural production. Heat stress transcription factors (HSFs) represent a critical regulatory juncture in the heat stress response (HSR) of plants. The HsfA1-dependent pathway has been explored well, but the regulatory mechanism of the HsfA1independent pathway is still under-investigated. In the present research, HsfA4, an important gene of the HsfA1-independent pathway, was isolated from lilies (Lilium longiflorum) using the RACE method, which encodes 435 amino acids. LlHsfA4 contains a typical domain of HSFs and belongs to the HSF A4 family, according to homology comparisons and phylogenetic analysis. LlHsfA4 was mainly expressed in leaves and was induced by heat stress and $\mathrm{H}_{2} \mathrm{O}_{2}$ using qRT-PCR and GUS staining in transgenic Arabidopsis. LlHsfA4 had transactivation activity and was located in the nucleus and cytoplasm through a yeast one hybrid system and through transient expression in lily protoplasts. Over expressing LlHsfA4 in Arabidopsis enhanced its basic thermotolerance, but acquired thermotolerance was not achieved. Further research found that heat stress could increase $\mathrm{H}_{2} \mathrm{O}_{2}$ content in lily leaves and reduced $\mathrm{H}_{2} \mathrm{O}_{2}$ accumulation in transgenic plants, which was consistent with the up-regulation of HSR downstream genes such as Heat stress proteins (HSPs), Galactinol synthase1 (GolS1), WRKY DNA binding protein 30 (WRKY30), Zinc finger of Arabidopsis thaliana 6 (ZAT6) and the ROS-scavenging enzyme Ascorbate peroxidase 2 (APX2). In conclusion, these results indicate that LlHsfA4 plays important roles in heat stress response through regulating the ROS metabolism in lilies.
\end{abstract}

Keywords: lilium; heat stress; LlHsfA4; reactive oxygen species

\section{Introduction}

Heat stress is an abiotic stress that plants often encounter due to global warming; the appropriate temperature for normal plant growth and development is surpassed, causing irreversible damage to plants and reducing crop yield. In the long-term evolutionary process of resisting heat stress, plants have evolved a complex network of signal perception, transmission and transcriptional regulation in the molecular response to heat stress. Upon receiving heat stress signals, plant plasma membrane enhances its fluidity, promoting $\mathrm{Ca}^{2+}$ influx and forming primary signals that are transmitted downward through protein phosphorylation to heat stress transcription factors (HSFs), which activate the expression of downstream genes such as heat stress proteins and antioxidants to alleviate plants exhibiting tolerance to heat stress [1-3]. Reactive oxidative species (ROS) that act as a second messenger are also induced in heat stress response $[4,5]$. 
HSF genes are present in all eukaryotes, with only one or a few in yeast and animals, but dozens are present in plants, indicating the structural complexity and functional redundancy of plant HSFs [6]. When subjected to heat stress, plant HSFs specifically bind to the heat stress element (HSE) of heat stress downstream gene promoters and recruit other proteins to form transcriptional complexes to regulate their expression and response to heat stress [7]. The structure of plant HSFs are conserved and include several important domains such as the DNA binding domain (DBD), the oligomerization domain (OD), the nuclear localization signal (NLS), the nuclear export signal (NES) and the transcriptional activation domain (AHA) and OD domain contains hydrophobic repeat (HR) regions A/B which are required for oligomerization [8]. HSFs were classified into three classes, HSFA, HSFB and HSFC, according to the peculiarities of the OD, which mainly refers to the numbers of amino acid residues between the HR-A and HR-B parts [6]. HSFAs have AHA domains and transcriptional activation activity and HSFBs lack AHA domains and do not have transcriptional activation activity, which may interact with HSFAs as repressors in Arabidopsis and tomatoes [9-12]. HSFCs have been reported to play roles in different abiotic stresses such as salt stress and development in rice and wheat [6,13-15]. HSFAs play a major role in heat stress response and the number of HSFAs is the largest among these three classes.

Studies have shown that HSFA genes are central regulators of heat stress response in plants [6]. In model and crop plants such as Arabidopsis, tomato and soybean, HsfA1 expresses constitutively in a normal condition and elevates quickly due to heat stress and it plays critical roles mainly in basal heat tolerance [16-20]; HsfA2 and $H s f A 3$ are induced by heat stress and regulated by HsfA1, which could be key regulators in the establishment of acquired thermo-tolerance in plants [21-23]. HsfA1s also activate HsfA7, HsfBs, Multiprotein bridging factor 1c (MBF1c) and dehydration responsive element-binding protein 2a (DREB2a), which modulate the synthesis of heat stress response genes [19,24]. These genes are all regulated by HsfA1 and composed of HsfA1-dependent pathways in heat stress response, while other genes regulate thermotolerance independently of HSFA1, such as HsfA4, HsfA5 and $H s f A 9[3,25,26]$. Studies in different species suggest that HsfA4 may be involved in salt stress and heavy metal stress via ROS [27-29].

Plant ROS are chemically reactive oxygen metabolites and their derivatives, which are more reactive than oxygen atoms, mainly including hydrogen peroxide $\left(\mathrm{H}_{2} \mathrm{O}_{2}\right)$, superoxide anions $\left(\mathrm{O}_{2}{ }^{-}\right)$, hydroxyl radicals $\left(\mathrm{HO}^{-}\right)$and singlet oxygen $\left({ }^{1} \mathrm{O}_{2}\right)$. Heat stress induces large amounts of ROS in chloroplasts and mitochondria, which act as second messengers to activate heat stress response $[4,5]$. However, excessive ROS can damage plants, which cause a negative effect in plant responses to heat stress. atrbohB and atrbohD mutants, which are deficient in ROS-producing NADPH oxidizes in plant cell membranes, were sensitive to heat stress [1]. Ascorbate peroxidase (APX) and catalase (CAT) are two important classes of ROS scavenging enzymes and the double mutant ap 2 cat 2 has also reduced thermotolerance [30]. Zinc finger proteins ZAT12, ZAT7 and ZAT10 regulated the expression of $A P X s$ in heat stress response [31,32]. SNAC3 transcription factor in rice was induced by heat stress and reduced ROS damage by activating the expression of ROS scavenging enzyme genes [33]. These reports indicate that ROS is involved in plant response to heat stress through regulating ROS scavenging systems.

Lilies are colorful, fragrant flowers with a long growth period. The lily is one of four important cut flowers in the international flower market and is becoming increasingly popular in China [34-37]. Common cultivated cut lily species prefer a cool environment; for example, the suitable growth temperature of Oriental lilies is $25-28{ }^{\circ} \mathrm{C}$ during the day. Most regions in China have a continuous high temperature (more than $30^{\circ} \mathrm{C}$ ) in the summer that seriously affects lily growth and development, causing vanished buds and blind flowers, greatly affecting the quantity and quality of fresh cut lily flowers. Therefore, studying the molecular mechanism of heat stress response in lilies and breeding new heatresistant lily varieties through genetic improvement is an effective way to solve this problem. We have focused on HSFAs and, from Lilium longiflorum 'White Heaven', have cloned 
LlHsfA1, LlHsfA2a, LlHsfA2b, LlHsfA3A and LlHsfA3B, which are all involved in heat stress response by the HsfA1-dependent pathway $[20,22,23,38]$. In this study, we characterized another HSFA gene LlHsfA4, which participates in the HsfA1-independent pathway in lilies. The expression of LlHsfA4 was induced by heat and $\mathrm{H}_{2} \mathrm{O}_{2}$. Over expressing $\mathrm{LlHsfA4}$ in Arabidopsis improved the basic thermotolerance, reduced ROS content and up-regulated the expression of $A t A P X 2$, which indicates that LlHsfA4 could play important roles in heat stress response through regulating the expression of ROS scavenging enzymes to control ROS levels in lilies.

\section{Results}

\subsection{Molecular Cloning and Sequence Analysis of LlHsfA4}

The LlHsfA4 gene (Accession No.MZ970559) was cloned from Lilium longiflorum 'White Heaven' tissue culture seedlings by homologous cloning and rapid amplification of the cDNA ends (RACE) technique. The full-length sequence of LlHsfA4 contained a $5^{\prime}$-untranslated region (UTR) of $182 \mathrm{bp}$, a 3'-UTR region of $235 \mathrm{bp}$ and an open reading frame (ORF) region of $1311 \mathrm{bp}$, encoding a 436 amino acid protein. Homology comparison of the amino acid sequence revealed that LlHsfA4 contains all the core domains of heat stress transcription factor, including the DNA binding domain (DBD), the oligomerization domain (OD), the nuclear localization signal (NLS), activator peptide motifs (AHA) and the nuclear export signal (NES) regions (Figure 1A). LlHsfA4 was highly similar to HsfA4 in all of the five domains in monocotyledonous plants such as Elaeisguineensis, Phoenix dactylifera and Oryza sativa, while it was less conserved in the C-terminal region compared with the same protein in dicotyledonous plants such as Arabidopsis and Solanumly copersicum.

A

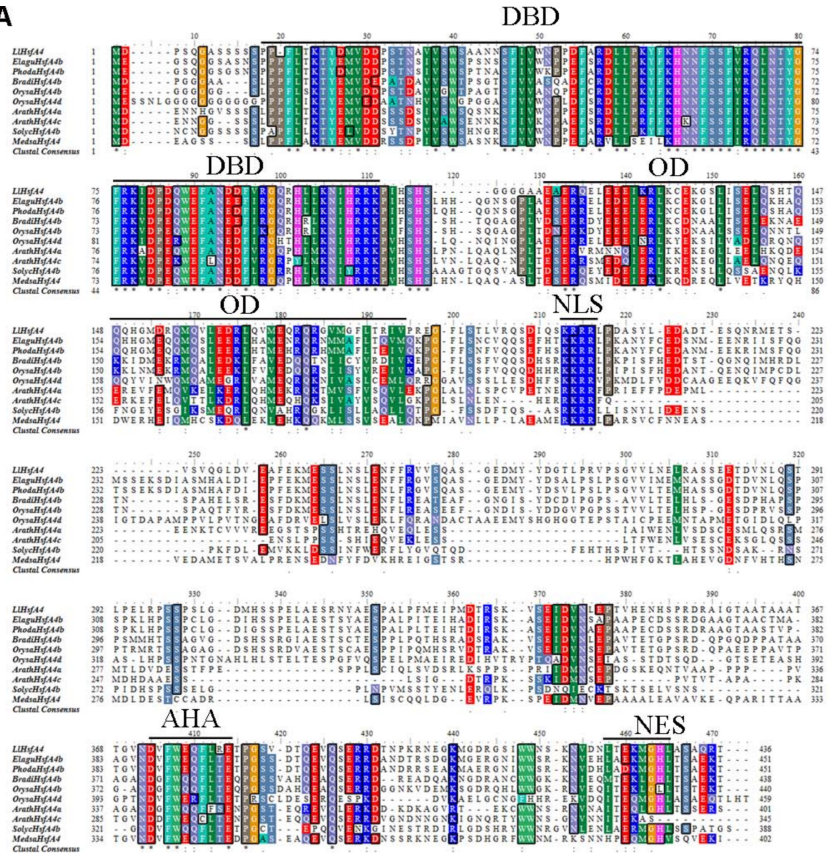

B

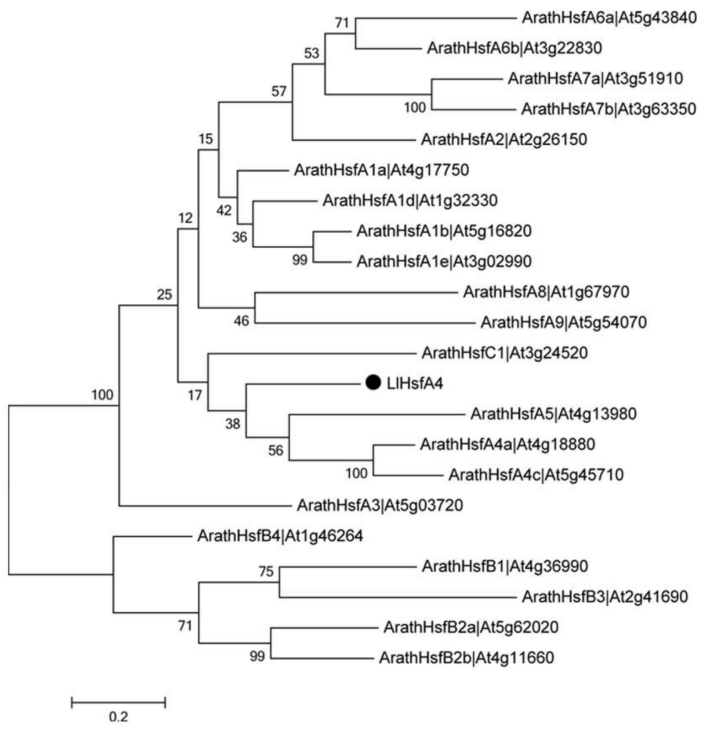

Figure 1. Alignment of amino acid sequence of HsfA4 in different plants. (A) Sequence alignment of LlHsfA4 with HsfA4 from Elaeis guineensis, Phoenix dactylifera, Brachypodium distachyon, Oryza sativa, Arabidopsis, Solanumly copersicum and Medicago sativa. The conserved DNA binding domain (DBD), the oligomerization domain (OD), the nuclear localization signal (NLS), activator peptide motifs (AHA) and the nuclear export signal (NES) are indicated by dark colored lines. (B) Phylogenetic tree of LlHsfA4 and all HSFs in Arabidopsis. This tree was constructed by ClustalW 2.0 and MEGA 5.0. The dark dot indicates an LlHsfA4 protein.

LlHsfA4 was the closest genetic association with the class A4 according to phylogenetic analysis with 21 heat-stress transcription factors reported in Arabidopsis, which provided 
a further hint that LlHsfA4 was a novel HSF protein (Figure 1B). The phylogenetic tree was also analyzed using HsfA4s from other reported species, which showed that LlHsfA4 was the closest to HsfA4s in monocotyledonous plants such as Asparagus officinalis, Elaeis guineensis, Phoenix dactylifera and Ananascomosus (Supplementary Figure S1). These analyses indicate that the cDNA cloned from lilies was the HsfA4 gene and was named LlHsfA4 to examine its function in heat stress response in Lilium.

\subsection{Expression Analysis of LlHsfA4}

To investigate the role of LlHsfA4 in heat stress response in lily plantlets under tissue culture, different expression patterns of $L l H s f A 4$ were analyzed, including organ expression and expression under heat stress. Organ expression was analyzed firstly and the organ mainly includes roots, bulbs and leaves. At normal temperature $\left(25^{\circ} \mathrm{C}\right), \mathrm{LlHsfA} 4$ expression was detected in all three organs and was highest in the leaves, compared to that in roots and bulbs (Figure 2A), suggesting that $L l H s f A 4$ constitutively expresses in all of the plantlets and mainly expresses in leaves that sense heat stress signal firstly. Thus, leaves were selected as the material to perform subsequent expression experiments.

A

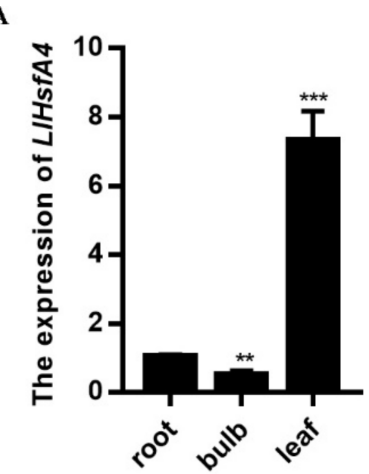

C

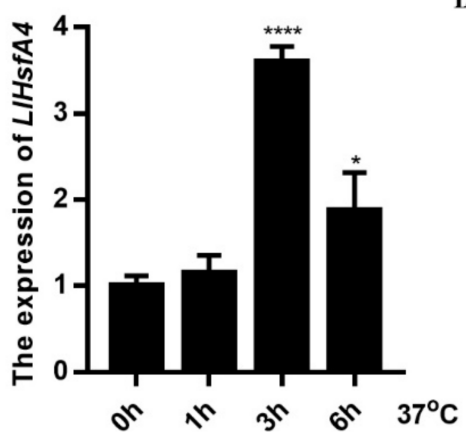

B
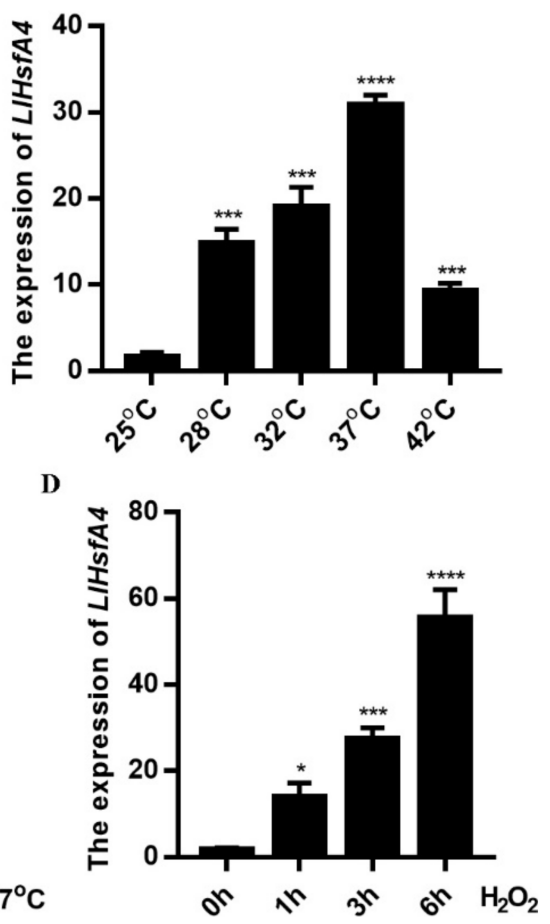

Figure 2. Expression analysis of HsfA4 in organs and heat stress condition by qRT-PCR. (A) Relative expression of LlHsfA4 in roots, bulbs and leaves. (B) Lily seedlings were treated with heat temperatures of $28{ }^{\circ} \mathrm{C}, 32{ }^{\circ} \mathrm{C}, 37^{\circ} \mathrm{C}$ and $42{ }^{\circ} \mathrm{C}$. (C) Lily seedlings were treated using $37^{\circ} \mathrm{C}$ for $1 \mathrm{~h}$, $3 \mathrm{~h}$ and $6 \mathrm{~h}$. (D) Lily seedlings were treated using $\mathrm{H}_{2} \mathrm{O}_{2}$ for $1 \mathrm{~h}, 3 \mathrm{~h}$ and $6 \mathrm{~h}$. $18 \mathrm{~S}$ rRNA was used as a control. Three independent experiments were performed each with three technical replicates, showing one experiment result. $t$-test analysis of variance was employed to identify treatment means that differed statistically. Samples with different letters are significantly different: ${ }^{*} p<0.05,{ }^{* *} p<0.01$, *** $p<0.001,{ }^{* * * *} p<0.0001$, Unmarked means non-significance.

In order to determine the expression pattern of LlHsfA4 under heat stress, small plantlets of lilies were subjected to heat treatment at different temperatures for three hours. Compared with $25^{\circ} \mathrm{C}$, expression of LlHsfA4 was enhanced at $28^{\circ} \mathrm{C}, 32{ }^{\circ} \mathrm{C}, 37^{\circ} \mathrm{C}$ and $42{ }^{\circ} \mathrm{C}$, reaching a peak at $37^{\circ} \mathrm{C}$, which increased 4.7 -fold (Figure 2B). Examination assay of mRNA levels of heat treatment at $37^{\circ} \mathrm{C}$ with different times were then carried out. The expression 
of $L l H s f A 4$ increased first and then decreased with the extension of heat treatment time and the expression level was the highest at $3 \mathrm{~h}$ (Figure 2C).

As ROS are important second messengers in heat stress response and since heat stress induces ROS accumulation, the expression of LlHsfA4 was detected in $\mathrm{H}_{2} \mathrm{O}_{2}$ treatment. Under $\mathrm{H}_{2} \mathrm{O}_{2}$ treatment, $L l H s f A 4$ expression was induced at $1 \mathrm{~h}$ and increased over 50-fold at $6 \mathrm{~h}$, which indicates that LlHsfA4 could be involved in the ROS pathway in heat stress response (Figure 2D).

To further identify the expression pattern and regulation of LlHsfA4, the promoter of LlHsfA4 was cloned using a high-tail technique in lilies. About $1.8 \mathrm{~kb}$ of the genomic DNA sequence upstream of the LlHsfA4 gene was isolated and analyzed for possible cis-elements using the PLACE data $[39,40]$. Unpredictably, there were no conserved HSE elements (AGAAnnTTCT) in the promoter, while cis-element associated hormone signals such as ABA-responsive element (ABRE), v-myb avian myeloblastosis viral oncogene homolog (MYB), anaerobic responsive element (ARE) and CGTCA-motif were found (Figure 3A). A pLlHsfA4-GUS binary vector was constructed and transformed into Arabidopsis and transgenic seedlings were then selected to determine activity of the LlHsfA4 promoter using GUS staining. GUS activity was detected in all organs including leaves and roots; it was higher in leaves and hypocotyls and lower in roots, which indicates the constitutive expression activity of the LlHsfA4 promoter (Figure 3B).GUS activity was also detected by different abiotic stresses such as heat, salt and osmosis (Figure 3C). The staining was higher only in heat stress, with no change under salt and osmotic stress compared with control, which means that LlHsfA4 could respond to heat stress specially. GUS staining was deepened gradually under heat and $\mathrm{H}_{2} \mathrm{O}_{2}$ treatment at different times (Figure 3D,E). These results are consistent with the qRT-PCR experiment with lilies (Figure 2), which indicated that LlHsfA4 expresses universally and is induced by heat and ROS.

A

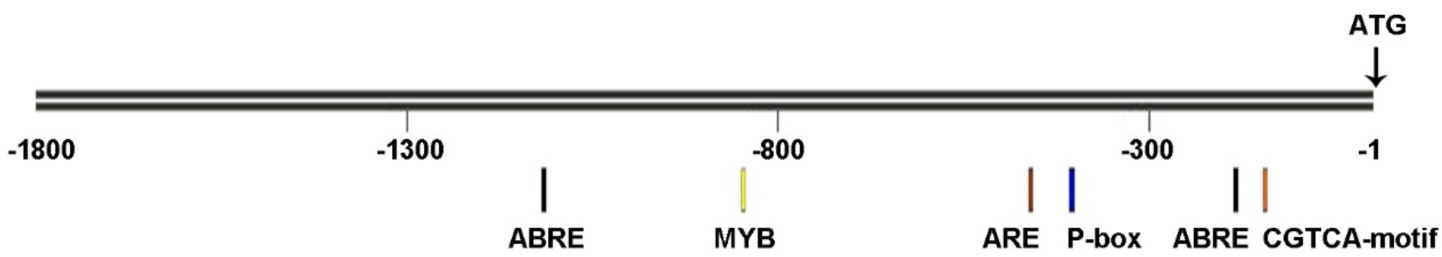

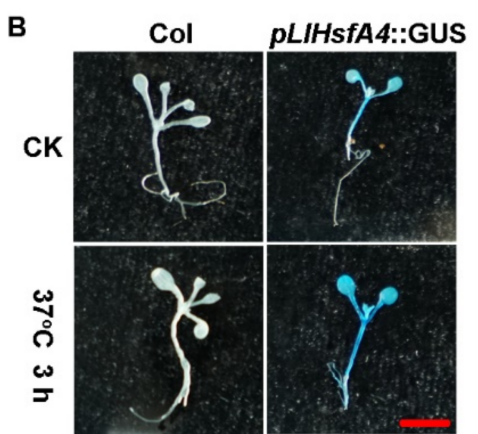

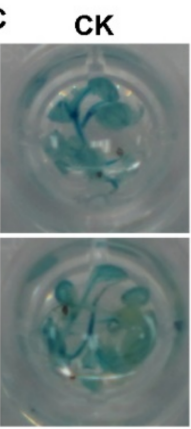

Mannitol

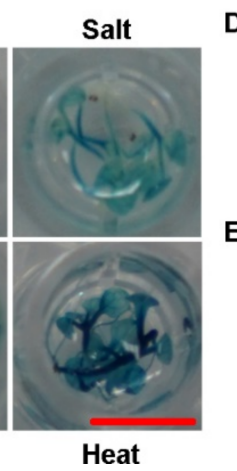

D

Figure 3. Expression analysis of HsfA4 using $p L l H s f A 4:$ GUS transgenic Arabidopsis. (A) Cis-element analysis of LlHsfA4 promoter using PLACE data. GUS staining of pLlHsfA4::GUS transgenic Arabidopsis seedlings were treated with different abiotic stresses: heat stress in (B-D), salt(150 mM $\mathrm{NaCl})$ and osmosis (300 mM Mannitol) in (C) and $\mathrm{ROS}\left(1 \mathrm{mM} \mathrm{H}_{2} \mathrm{O}_{2}\right)$ in (E). Bar: $50 \mathrm{~mm}$.

\subsection{LlHsfA4 Localized to the Nucleus and Exhibited Transactivation Activity}

In order to further study the function of the HsfA4 protein, the subcellular localization of LlHsfA4 was investigated using two transient transformation assays. A binary vector containing LlHsfA4::eGFP driven by a super promoter was constructed. The fusion vector and a control vector were purified using a plasmid extraction kit and were tran- 
siently expressed in lily leaf protoplast cells using the PEG-Ca ${ }^{2+}$ method. As shown in Figure 4A, the LlHsfA4::eGFP signal was mainly localized in the nucleus, while the control GFP was localized in the nucleus and the plasma membrane. Another transient expression system of $N$. benthamiana was also used to confirm the localization. The vector was transformed into Agrobacterium and infected in N. benthamiana to observe the fluorescent signal. LlHsfA4::GFP was observed only in the nucleus and the green fluorescent was overlapped with the red fluorescent of nuclear localization marker NF-YA4-mcherry [41] (Figure 4B).While the control GFP was observed in the entire cell (Figure 4B). These results indicated that LlHsfA4 is a nuclear localization protein, which is consistent with its function of transcription factors.
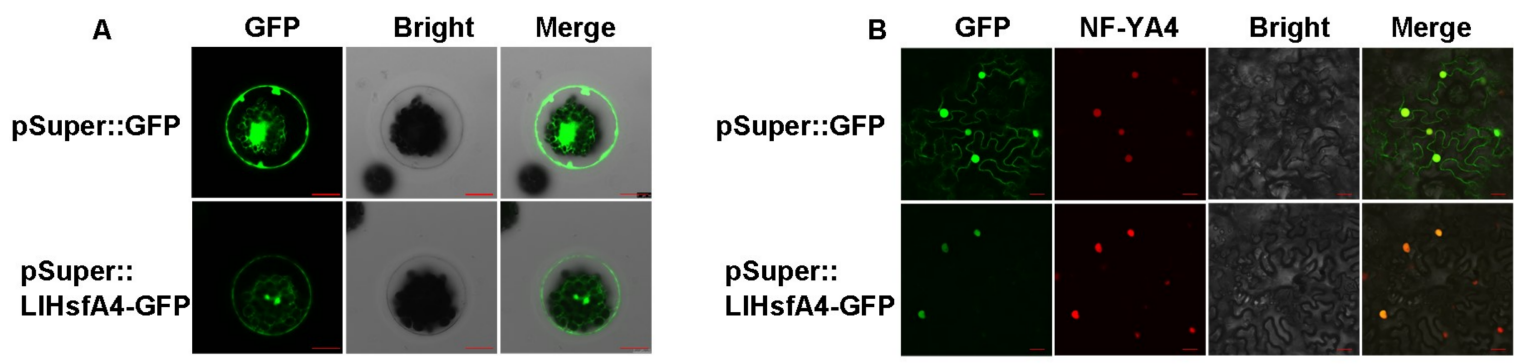

Figure 4. Subcellular localization of LlHsfA4. LlHsfA4-eGFP fusion protein was localized in the nucleus of a lily mesophyll protoplast (A) and N. benthamiana (B). Bar: $20 \mu \mathrm{m}$.

Homologous proteins of HsfA4 in plants such as Arabidopsis [42], rice [43], wheat [44] and tomato [25] all have transcriptional activation activity. As LlHsfA4 is localized in the nucleus, it is speculated that LlHsfA4 may also have a transcriptional activation function. The activation activity of LlHsfA4 was detected by the yeast system. The results in Figure 5 show that all the transformed yeast could grow normally on a SD/-Trp plate. On the $\mathrm{SD} /$-Trp-His select plate, the yeasts transformed with pBD-L1HsfA4 (FL) or pBD-GAL4 of the recombinant plasmids were able to grow normally, while the yeasts transformed with the negative control pGBKT7 plasmid did not. In the presence of X-Gal, yeast transformed with the pBD-LlHsfA4 (FL) and pBD-GAL4 recombinant plasmids turned blue within $8 \mathrm{~h}$, while that transformed with pGBKT7 could not and the $\beta$-galactosidase activity of pBD-LlHsfA4 was much higher than that of pBD-GAL4 (Figure 5B). The results show that LlHsfA4 had transcriptional activation activity.

In order to further determine the transcriptional activation region of LlHsfA4, four short truncations of this protein were constructed in units of 50 amino acids from the C-terminal, including D1 (370 amino acid), D2 (320 amino acid), D3 (270 amino acid) and D4 (220 amino acid), none of which contain an AHA motif (Figure 5A). All of the short truncations were constructed into a pGBKT7 vector and performed a yeast one hybrid assay. The results in Figure 5B, D1 and D2 show transcriptional activation activity, while D3 and D4 had no transcriptional activation activity in X-Gal staining, which means that there is a transcriptional activation region was located between 320th and 370th amino acids. The activity of $\beta$-galactosidase was further measured to confirm this result. The transcriptional activity of D1 and D2 was significantly decreased compared to that of the full-length protein, which may be related to the deletion of the AHA motif in D1 (370th amino acid to the terminator) and this is consistent with predictions and previous reports. Another decrease occurred between D2 and D3. There may be another transcription activation domain located in the region between 270th and 320th amino acids, which were not predicted (Figure 5B). These results indicated two transcription activation domains in LlHsfA4: one is the predicted AHA in the C-terminal and the other is in the region between 270th and 320th amino acids. 


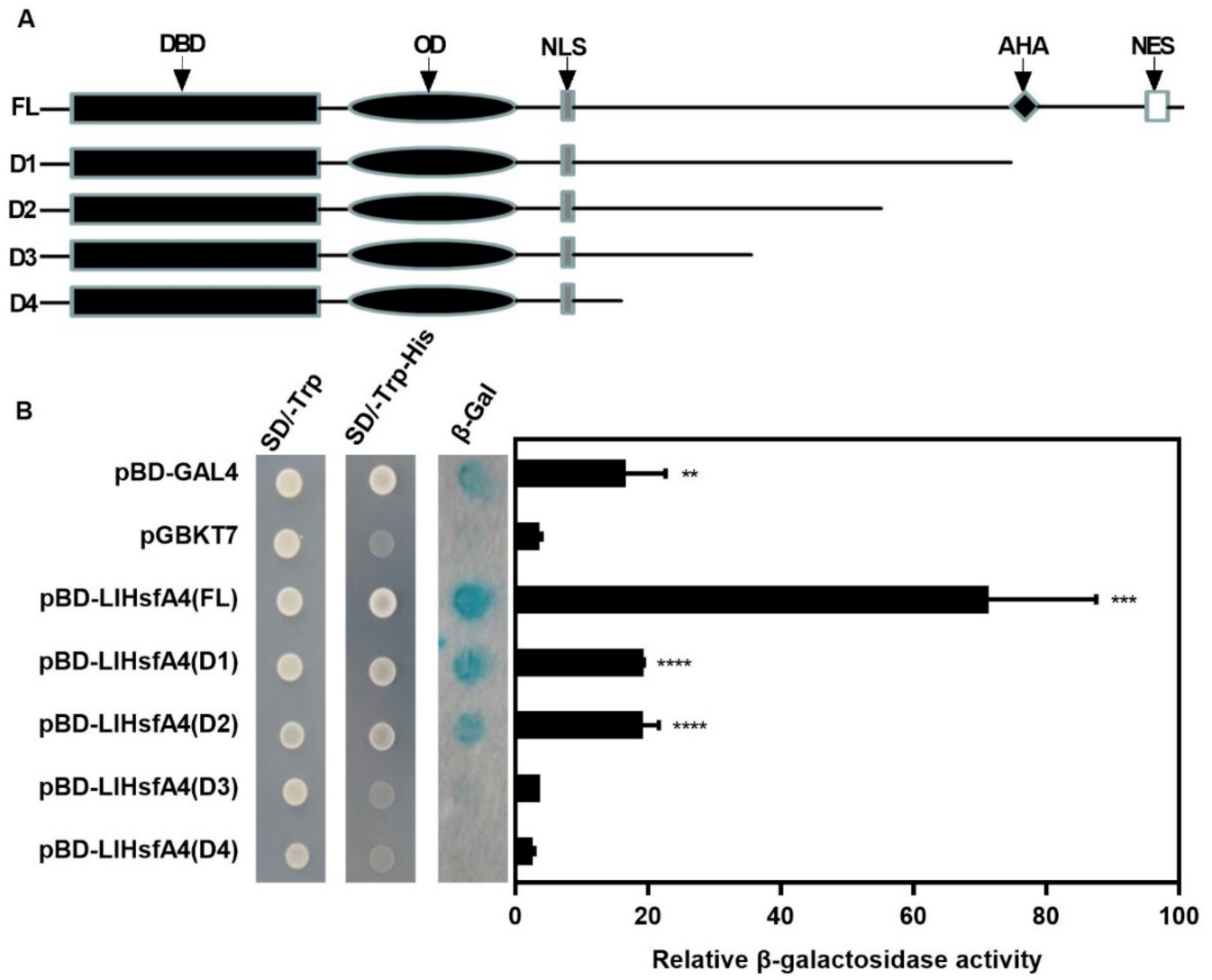

Figure 5. Transactivation activity of LlHsfA4 in the yeast strain AH109. (A) Different deletion forms of LlHsfA4 were constructed for the transcriptional activation assay. (B) Transactivation activity of different constructs were examined in yeast and the $\beta$-galactosidase activity of the transformed yeast cells was detected and measured. The transformed yeast cells were grown in a SD medium with or without histidine and X-gal staining was used for detecting $\beta$-gal activity. $\beta$-gal activity was measured through an enzyme assay. Three independent experiments were performed, each with three technical replicates, showing one experiment result. T-test analysis of variance was employed to identify treatment means that differed statistically. Samples with different letters are significantly different: ${ }^{* *} p<0.01,{ }^{* * *} p<0.001,{ }^{* * * *} p<0.0001$, Unmarked means non-significance.

\subsection{Overexpression of LlHsfA4 Enhanced the Basal Thermotolerance of Transgenic Arabidopsis Plants}

To test the function of LlHsfA4 in heat stress, LlHsfA4 under the control of the super promoter was transformed into Arabidopsis thaliana wild-type Col by the Agrobacteriummediated floral-dip method. Transgenic lines were screened by Hygromycin and the expression of LlHsfA4 in transgenic lines was detected by qRT-PCR. Two independent lines, A4-12 and A4-43, were chosen for heat stress phenotypic observation with a high expression level (Figure 6A). Firstly, the phenotypes of the basal thermotolerance of the transgenic plants were examined using 5-day old seedlings that were exposed to $45^{\circ} \mathrm{C}$ for $70 \mathrm{~min}$ and transferred to a normal growth environment $\left(22^{\circ} \mathrm{C}\right)$. After 7 days, two transgenic lines survived well, while almost of the wild-type Col died (Figure 6B). The survival rates of two transgenic lines were over $50 \%$, which is significantly higher those of the wild type (Figure 6C). An acquired thermotolerance assay was then carried out. With different times of $45^{\circ} \mathrm{C}$ treatment, there were no differences between the transgenic lines and the wild type (Supplementary Figure S2), which means that LlHsfA4 was not involved in the acquired thermotolerance. These assays implied that LlHsfA4 plays important roles in the basal thermotolerance process. 


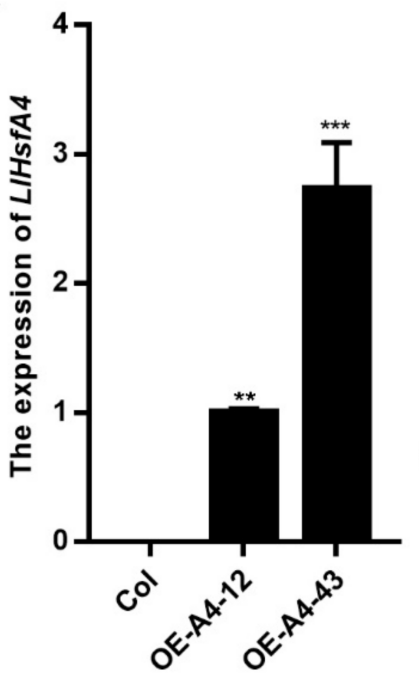

B

Before HS

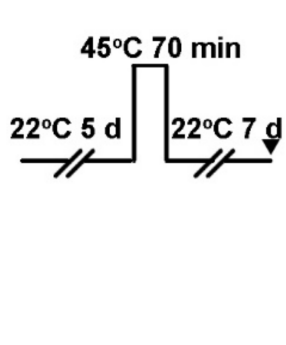

C

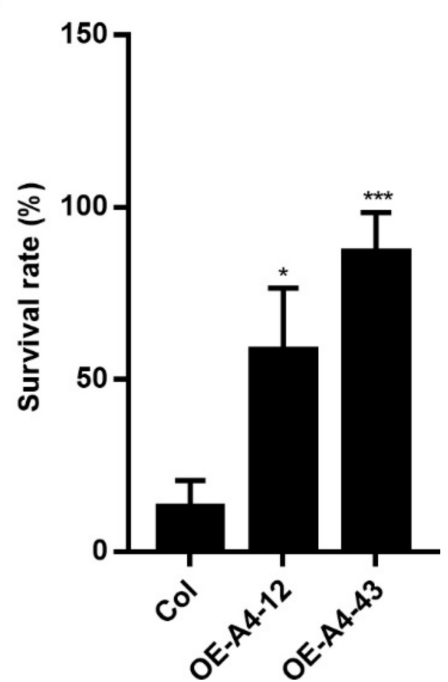

Figure 6. Transgenic Arabidopsis plants of LlHsfA4 enhanced basal thermotolerance. (A) Overexpression of LlHsfA4 in transgenic lines was examined using qRT-PCR. (B) Images of two transgenic lines and the wild type $(\mathrm{Col})$ under normal conditions and recovery for $7 \mathrm{~d}$ after heat stress. (C) Survival rates of transgenic lines were calculated in (B). $t$-test analysis of variance was employed to identify treatment means that differed statistically.Samples with different letters are significantly different: ${ }^{*} p<0.05,{ }^{* *} p<0.01,{ }^{* * *} p<0.001$.

In order to search the molecular mechanism of LlHsfA4, improving the basal thermotolerance of transgenic Arabidopsis, the expression of heat stress response downstream genes in transgenic lines was detected by qRT-PCR (Figure 7). Four small HSP genes (AtHsp19.9, AtHsp22, AtHsp25.3 and AtHsp17.6), AtGolS1, AtMBF1c, AtWRKY30, AtZAT6 and AtZAT12 were examined in WT and transgenic lines. The expression of heat stress-related genes increased in transgenic lines compared with the wild type (Figure 7) and it was lower in Line A4-12, while the expression in Line A4-43 was higher, which is consistent with the expression of LlHsfA4 in the transgenic lines (Figure 6A). This result indicated that the expression of HSR downstream genes was positively correlated with the expression level of LlHsfA4 in transgenic lines, which enhanced the heat stress phenotype of transgenic Arabidopsis.

\subsection{Accumulation of $\mathrm{H}_{2} \mathrm{O}_{2}$ Was Reduced in LlHsfA4 Transgenic Arabidopsis Plants}

In the transgenic lines of LlHsfA4, the expression of AtZAT6 was higher than that of the wild type, while the expression of AtZAT12 did not change. AtZAT6 and AtZAT12 were required for the expression of $A P X s$ in heat stress response in the existing reports. Thus, it could be speculated that heat stress could promote the accumulation of $\mathrm{H}_{2} \mathrm{O}_{2}$ in lilies according to the above result. Firstly, $\mathrm{H}_{2} \mathrm{O}_{2}$ content was detected by DAB staining in 'White Heaven' tissue culture seedlings (Figure 8A) and the content of $\mathrm{H}_{2} \mathrm{O}_{2}$ was accumulated with $37^{\circ} \mathrm{C}$ treatment, which is similar to the result of $\mathrm{H}_{2} \mathrm{O}_{2}$ treatment. This result was verified with the discs from mature leaves of cut flowers 'Siberia' (Figure 8B) and the heat stress and $\mathrm{H}_{2} \mathrm{O}_{2}$ treatment could enhance the $\mathrm{H}_{2} \mathrm{O}_{2}$ content in lily plants. In addition, superoxide anions $\left(\mathrm{O}_{2}{ }^{-}\right)$was examined by NBT staining in 'White Heaven' tissue culture seedlings (Figure 8A), which content was increased with $37^{\circ} \mathrm{C}$ treatment and $\mathrm{H}_{2} \mathrm{O}_{2}$ treatment. These result indicated that ROS could be involved in heat stress response. 
A

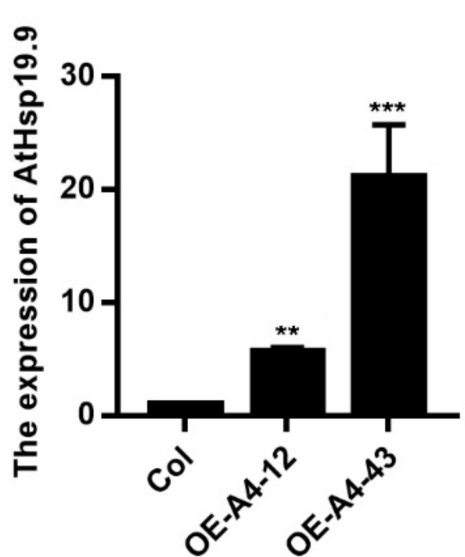

D

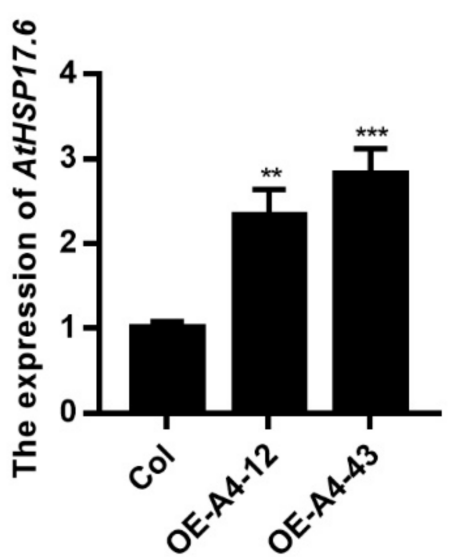

G

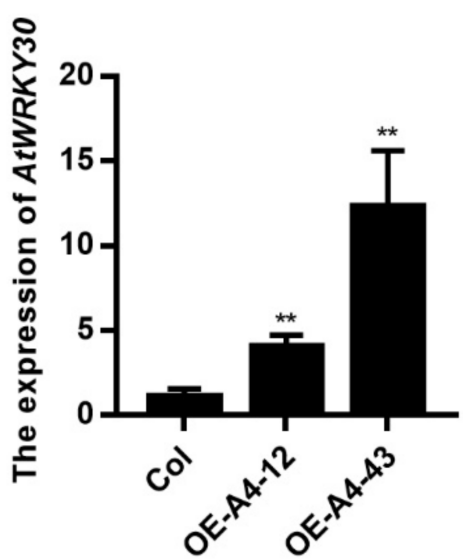

B

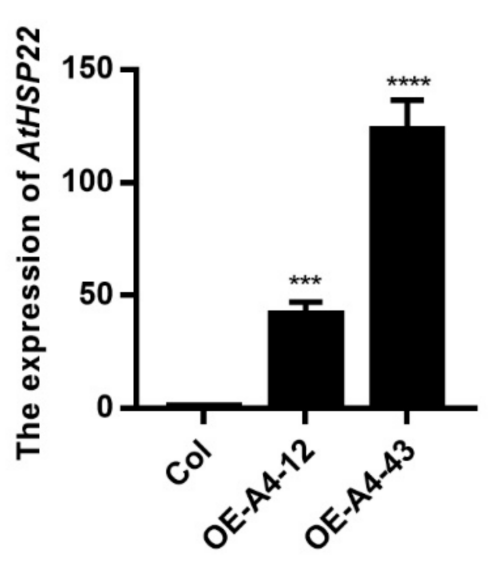

E

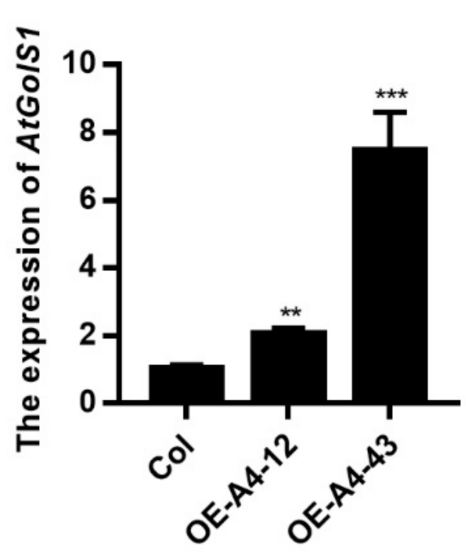

H

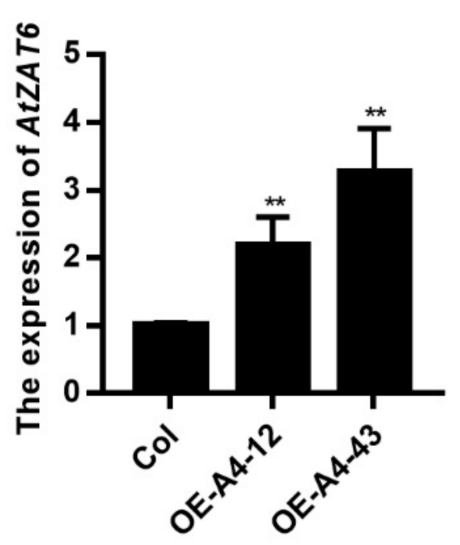

C

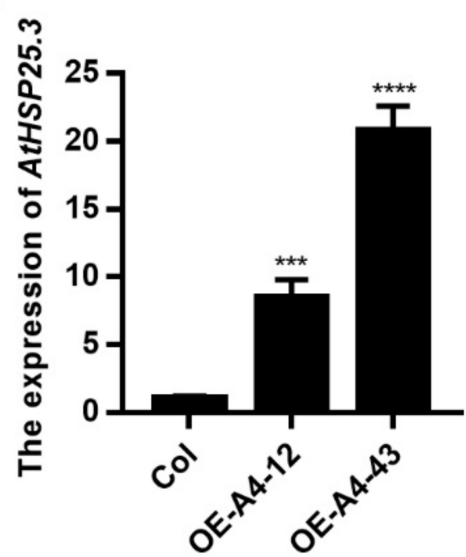

F

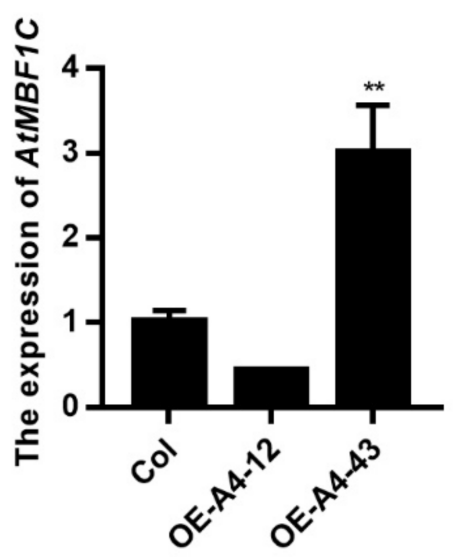

$1 \stackrel{1}{2}$

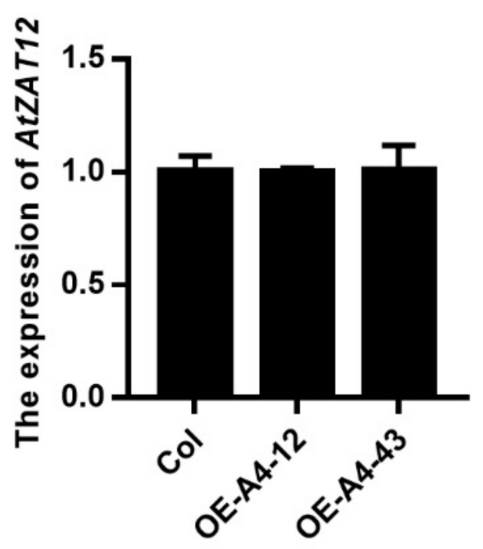

Figure 7. Expression of target genes was examined in LlHsfA4 transgenic plants. (A-I) showed the expression levels of 9 target genes..The mRNA level of target genes was detected in wild type $(\mathrm{Col})$ and transgenic lines using qRT-PCR. The expression value of these genes in Col was set as1 for comparison and AtACTIN2 was used as an internal standard. 10-day-old seedlings were collected for RNA extraction. Three independent experiments were performed, each with three technical replicates, showing one experiment result. $t$-test analysis of variance was employed to identify treatment means that differed statistically. Samples with different letters are significantly different: ${ }^{* *} p<0.01,{ }^{* * *} p<0.001,{ }^{* * * *} p<0.0001$, Unmarked means non-significance. 
A

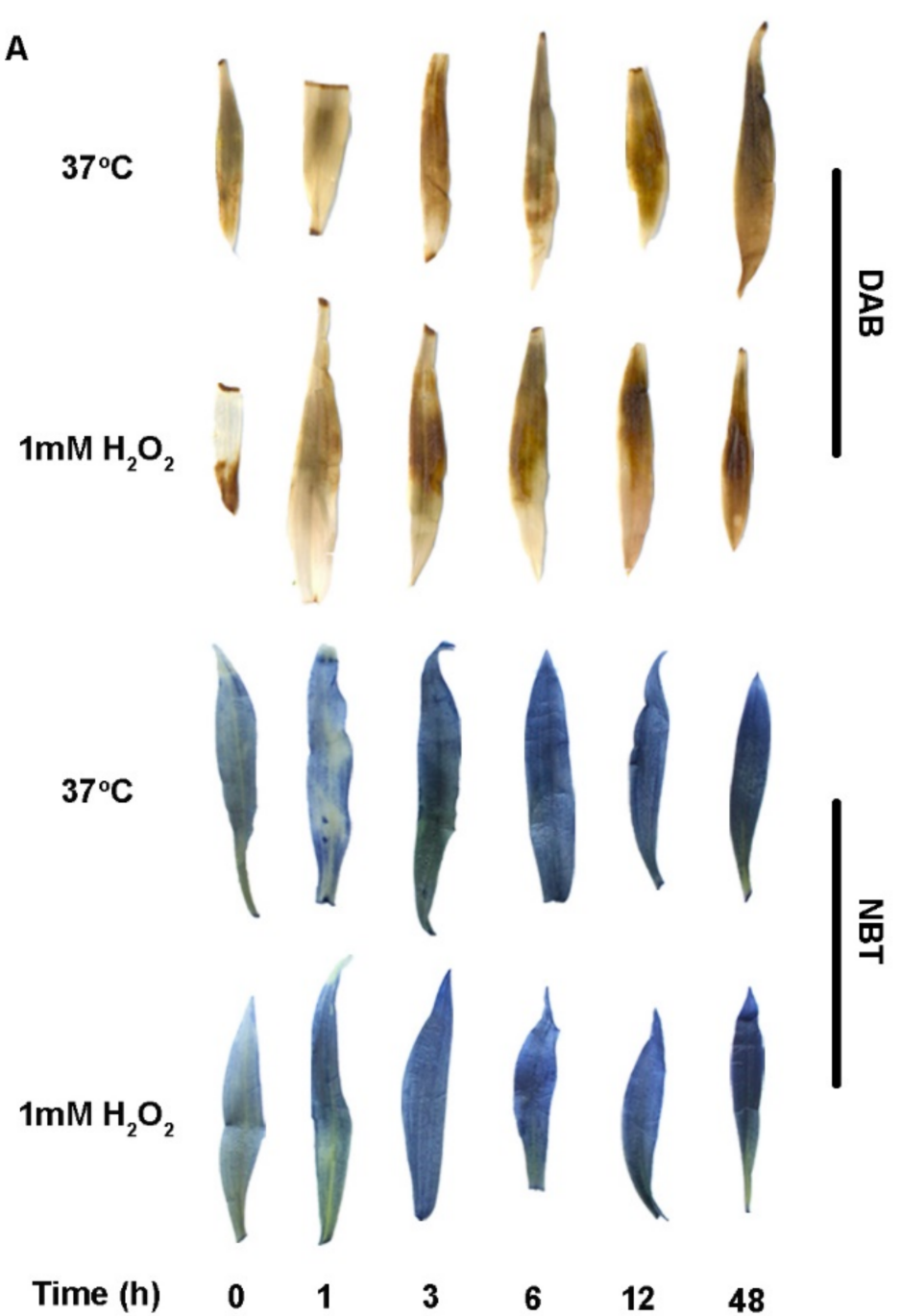

Time (
B

Con

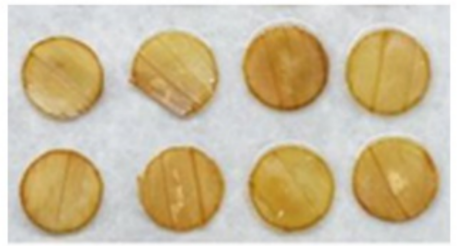

$37^{\circ} \mathrm{C}$

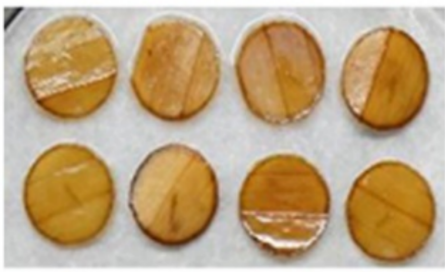

$\mathrm{H}_{2} \mathrm{O}_{2}$

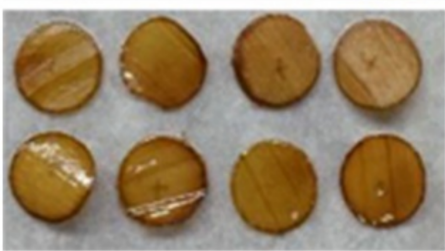

C

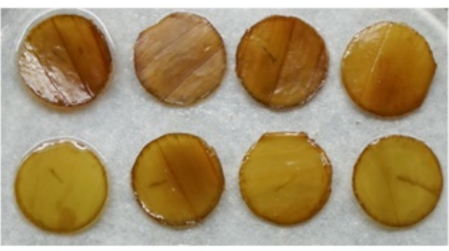

pSuper::

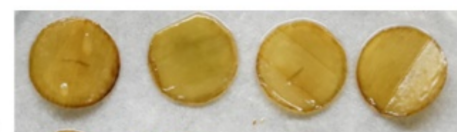

LIHsfA4

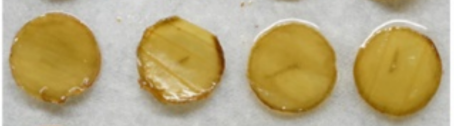

Figure 8. Content of ROS detected in lilies. (A) Leaves of 'White Heaven' tissue culture seedlings were stained by DAB staining or NBT staining under heat $\left(37^{\circ} \mathrm{C}\right)$ and $\mathrm{H}_{2} \mathrm{O}_{2}$ treatment. (B) Discs from mature leaves of cut flowers 'Siberia' were stained by DAB staining under heat $\left(37^{\circ} \mathrm{C}\right)$ and $\mathrm{H}_{2} \mathrm{O}_{2}$ treatment. (C) Discs from mature leaves of cut flowers 'Siberia' were stained by DAB staining under transient expression with $\mathrm{LlHsfA} 4$ under heat $\left(37^{\circ} \mathrm{C}\right)$ treatment.

The binary vector containing LlHsfA4 under the control of the super promoter was transformed into leaf discs for transient expression and $37^{\circ} \mathrm{C}$ treatment induced $\mathrm{H}_{2} \mathrm{O}_{2}$ content in the control discs, while $\mathrm{H}_{2} \mathrm{O}_{2}$ content reduced in discs over expressing $\mathrm{LlHsfA4}$ (Figure $8 \mathrm{C}$ ), which means that the accumulation of $\mathrm{H}_{2} \mathrm{O}_{2}$ was inhibited with the appearance of LlHsfA4. To confirm this result, leaves of transgenic plants were used for DAB staining. At heat $\left(37^{\circ} \mathrm{C}\right)$ and $\mathrm{H}_{2} \mathrm{O}_{2}$ treatment, $\mathrm{H}_{2} \mathrm{O}_{2}$ content was decreased in all transgenic lines (Supplementary Figure S4), which was consistent with the transient expression. There are many ROS-related scavenging enzymes, including eight ascorbate peroxidases (AtAPXs). They were used to examine their expression to identify which ones could be regulated by HsfA4; the result showed that only the expression of AtAPX2 was higher in the two transgenic lines than that of the wild type (Figure 9 and Figure S5). These results indicated that HsfA4 could regulate the expression of APX2 to control the ROS level and thus improve heat stress of plants. 

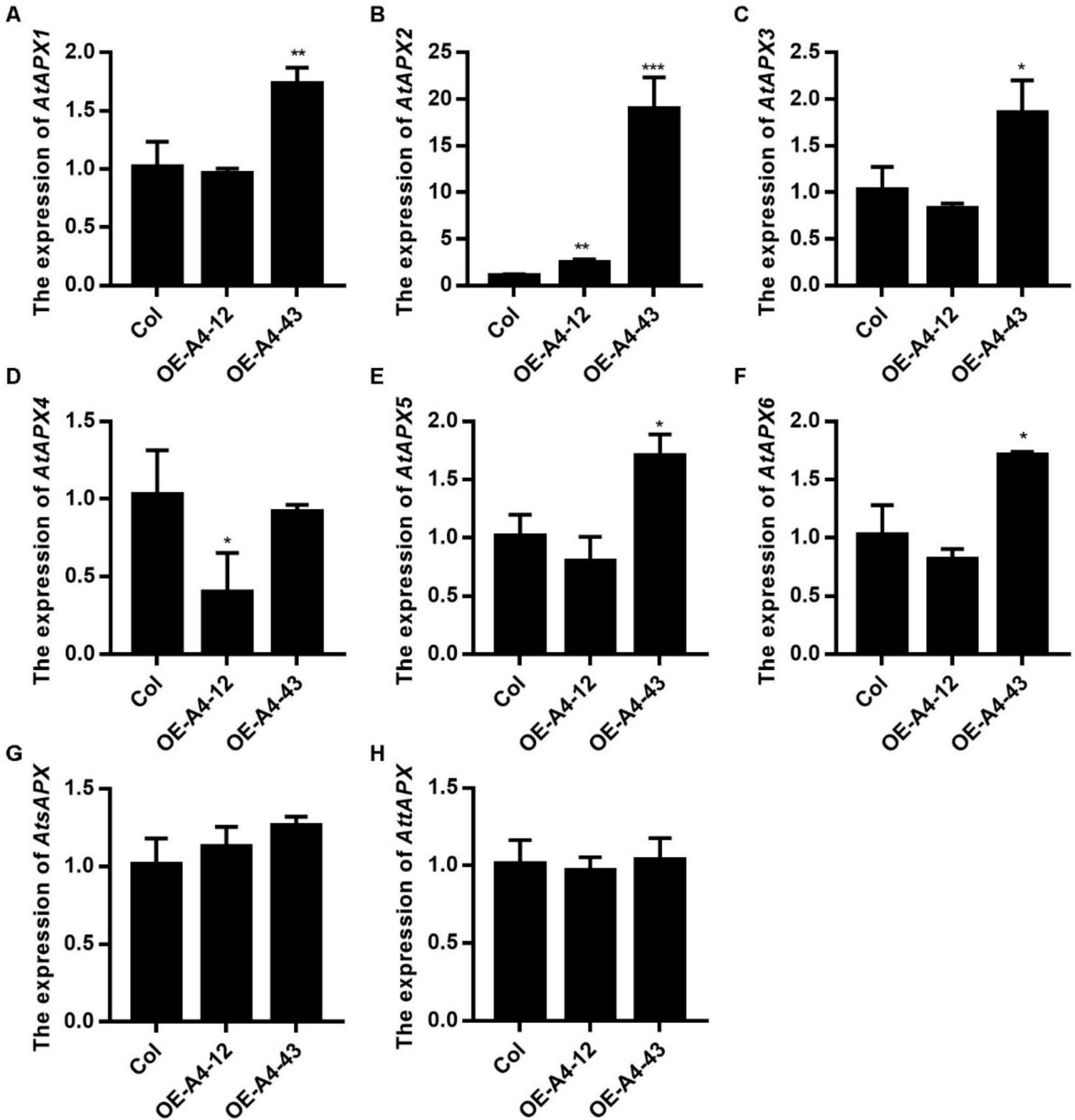

Figure 9. Expression of AtAPXs was examined in LlHsfA4 transgenic plants. (A-H) show the Expression levels of 8 AtAPXs. The mRNA level of AtAPXs was detected in wild-type (Col) and transgenic lines using qRT-PCR. The expression values of these genes in Col were set as 1 for comparison and AtACTIN2 was used as an internal standard. 10-day-old seedlings were collected for RNA extraction. Three independent experiments were performed, each with three technical replicates, showing one experiment result. $t$-test analysis of variance was employed to identify treatment means that differed statistically. Samples with different letters are significantly different: ${ }^{*} p<0.05,{ }^{* *} p<0.01,{ }^{* * *} p<0.001$, Unmarked means non-significance.

We can conclude that LlHsfA4 may enhance the basal thermotolerance of Arabidopsis by directly increasing the expression of heat stress response genes and may improve the basal thermotolerance of Arabidopsis by reducing the accumulation of $\mathrm{H}_{2} \mathrm{O}_{2}$. 


\section{Discussion}

\subsection{LlHsfA4 Is a New HSF Transcription Factor in Lilies}

Plants have evolved a variety of molecular mechanisms in response to heat stress which affects the growth and development of plants. HSFs are important regulatory factors in heat stress response and they are divided into HsfA1-dependent and HsfA1-independent groups [3]. In the previous study, we cloned LlHsfA1, LlHsfA2a, LlHsfA2b, LlHsfA3a and $L l H s f A 3 b$ from lilies $[20,22,23,38]$ and they were all involved in thermotolerance and belong to the HsfA1-dependent group. In this article, we cloned LlHsfA4, encoding a new HSF transcription factor belonging to the HsfA1-independent pathway. LlHsfA4 has conserved domains of HSFs such as DBD and OD in the N-terminus, NLS in the middle and AHA and NES in the C-terminus (Figure 1). The subcellular localization assay and transactivation assay showed that LlHsfA4 was mainly localized in the nucleus and had transcriptional activation activity with two transcription activation domains (Figures 4 and 5). These results suggest that LlHsfA4 is a new HSF transcription factor in lilies.

The promoter of LlHsfA4 was cloned and analyzed using GUS staining and the result showed that LlHsfA4 expressed in all organs, was higher in leaves and hypocotyls and was lower in roots (Figure 3B or Figure 2A) and induced by heat in leaves more than roots, which is different from the PuHsfA4 induced in Populus roots by zinc [28]. The expression of $L l H s f A 4$ was significantly induced by heat, but it did not increase in response to $\mathrm{NaCl}$ and mannitol stresses (Figure 3C), which means that promoter of LlHsfA4 does not respond to salt stress as the homologous gene in Arabidopsis and Chrysanthemum [27,45]. While the over expressing LlHsfA4 lines grew better than the wild type under $200 \mathrm{mM} \mathrm{NaCl}$ treatment (Supplementary Figure S3), which indicates that LlHsfA4 could response to salt stress that need more assays to identify the mechanism. This difference could be explained by the different kinds of plant families. Additionally, no HSE elements were found in the promoter of LlHsfA4 (Figure 3A), which was similar to the promoter of AtHsfA4 in Arabidopsis, meaning that the expression of $H s f A 4$ could not be regulated by HsfA1, consistent with the classification of HsfA4 to HsfA1-independent transcription regulation networks [3,46].

\subsection{LlHsfA4 Plays Important Roles in Basal Thermotolerance}

HSFs are known to regulate heat stress response in different plants species and the expression of LlHsfA4 was induced by heat. LlHsfA4 could be involved in the adapting process in high-temperature conditions in lilies. In this study, the function of LlHsfA4 was analyzed by over-expressing LlHsfA4 in Arabidopsis. Transgenic Arabidopsis lines grew to a greater extent than the wild type and the survival ratio was higher than that of the wild type under basal thermo-tolerance treatment (Figure 6), while there were no differences between the transgenic lines and wild-type in the acquired thermotolerance assay (Supplementary Figure S2). These heat treatment assays indicated that LlHsfA4 plays important roles in heat stress responses in lilies, especially in basal thermo tolerance.

Downstream genes of HSFs such as AtGolS1, AtMBF1c, AtWRKY30, AtZAT6 and AtZAT12 were examined in this study. The expression of almost these genes increased in the over expressing LlHsfA4 lines, which is consistent with the phenotype of the basal thermo-tolerance of the transgenic lines, indicating that LlHsfA4 could enhance heat tolerance by regulating the expression of these genes. In Arabidopsis, the expression levels of HSP17.6, ZAT6, ZAT12 and WRKY30 are much higher in AtHsfA4 over-expressing lines than those in the wild type and heat treatment reduces this expression difference [47]. It has also been reported that a high temperature and salt can promote HsfA4 binding to the promoters of HSP17.6, ZAT12 and WRKY30, respectively, and the combined action of high temperature and salt increased these bindings [45]. These results suggest that HsfA4 is involved in different abiotic stress responses by regulating the same downstream gene expression. 


\subsection{LlHsfA4 Could Regulate ROS Levels through Inducing the Expression of APX}

HsfA4 plays important roles in salt stress, oxidative stress and heavy metal stress in several reported studies, which may be related to the metabolism balance of ROS. In monocotyledonous plants, TaHsfA4a in wheat (Triticum aestivum) and its homologous gene OsHsfA4a in rice (Oryza sativa) were obtained by screening Cd tolerance genes, which participate in Cd tolerance by regulating expression of the metallothionein gene MT-1. Further experiments showed that Cd tolerance of HsfA4 was related to Ala 31 and Leu 42 in the DBD domain [44]. In Populus, PuHsfA4 reduced ROS in roots by regulating the expression of glutathione-S-transferase U17 (PuGSTU17) and phospholipase A2 (PuPLA2), thereby activating the antioxidant system and promoting zinc tolerance [28]. In chrysanthemum, $\mathrm{CmHsfA4}$ reduces ROS levels by inducing ROS scavengers such as SODs, APXs and CATs [27]. In this study, $\mathrm{H}_{2} \mathrm{O}_{2}$ was detected in leaves of tissue culture seedlings and leaf discs of cut flower using DAB staining. High temperatures promoted the accumulation of $\mathrm{H}_{2} \mathrm{O}_{2}$ in lilies, which is similar to the phenotype of exogenous $\mathrm{H}_{2} \mathrm{O}_{2}$ treatment, indicating that ROS were important second messengers in the process of heat stress response. High temperature treatment reduced the $\mathrm{H}_{2} \mathrm{O}_{2}$ content of Arabidopsis transgenic lines of LlHsfA4. Similarly, high temperature treatment also reduced the $\mathrm{H}_{2} \mathrm{O}_{2}$ content in lily leaf discs with a transient over expression of LlHsfA4. These results are the same as those reported in previous studies, indicating that LlHsfA4 may be involved in the degradation of ROS during heat stress responses in Lilies.

Subsequently, we detected the gene expression of enzymes related to ROS metabolism in transgenic lines, such as APXs, SODs, CATs and GRs. Most genes did not change their expression in transgenic lines, but $A P X 2$ did (Figure 9 and Figure S5). There are eight isoforms of APXs in Arabidopsis, three cytosolic types (APX1, APX2 andAPX6), two chloroplast types (stoma sAPX and thylakoid tAPX) and three microsomal types (APX3, APX4 andAPX5) [48]. Among these eight genes, the expression of $A P X 2$ was increased in all transgenic lines, while the expression of $A P X 1, A P X 3, A P X 5$ and $A P X 6$ was only increased in A4-43, which has the highest level of LlHsfA4 in the two transgenic lines. The expression of $A P X 2$ in transgenic lines is much higher than that in the wild type and the expression of other APXs is about twice of that in the wild type, which means that the expression of $A P X$ is related to the expression of LlHsfA4. A higher expression of LlHsfA4 induced a higher expression of $A P X s$, indicating that $A P X 2$ may be a potential target gene of LlHsfA4. We tried to amplify the promoter of APXs and found that there was a long intron in the $5^{\prime}$ sequence of the genome DNA $[49,50]$ and it was difficult to use Hi-tail PCR to obtain the promoter. The regulation mechanism of APXs by LlHsfA4 needs further research.

\subsection{Complexity of Relationship between LlHsfA4 and ROS in Heat Stress Response}

HsfA4 has been shown to participate in ROS signals by regulating the expression of metabolically related ROS genes. According to existing articles, HsfA4 mediates ROS metabolism by inducing ZAT12 and APX1, of which ZAT12 regulates the expression of $A P X 1$ as a transcriptional inhibitor $[31,32,47]$. Moreover, HsfA4 can bind to the promoter of ZAT12 to activate ZAT12 expression [45]. Our result showed that the expression of ZAT6 and APX2 was higher in LlHsfA4 over expression lines than in the wild type (Figures 7 and 9), indicating that LlHsA4 could regulate ROS degradation through ZAT6 and is located upstream of the ROS signals. Whether LIHsfA4 can directly regulate APX or through ZAT6 regulating APX expression in lilies remains to be studied.

As second messengers, ROS have also been reported to play roles in responding to heat stress. Heat stress causes chloroplasts, mitochondria, peroxisomes and cell membranes to release ROS [46,51]. ROS from different cellular compartments can activate ANP1 (MAPK kinase kinase)-MAPK3/MAPK6 cascades to phosphorylate HsfA4a and activate the transcriptional activity of HsfA4a $[45,47,52,53]$, indicating that the protein activity of HsfA4 is regulated by ROS. In our experiment, the expression of LlHsfA4 is induced by $\mathrm{H}_{2} \mathrm{O}_{2}$ (Figures 2 and 3) and the promoter of LlHsfA4 contains ARE cis-acting elements, which is an anaerobic-induction-related cis-acting element related to hypoxia stress and 
flood hypoxia [54,55]. These results suggest that ROS can regulate the expression and protein activity of LlHsfA4 as a signal molecule.

Thus, the complex relationship between LlHsfA4 and ROS in lilies has been elucidated. When the content of ROS was excessive, as second messengers, ROS can transmit heat stress signals downward to activate $L l H s f A 4$ to regulate APX expression, which could degrade ROS to a controllable range and thus decrease the toxicity of those ROS. This feedback regulation not only ensures that lilies have sufficient energy to adjust their metabolism, but also ensures that these plants have an appropriate heat stress response.

\section{Materials and Methods}

\subsection{Plant Materials and Growth Conditions}

Longiflorum hybrid 'White heaven' (Lilium longiflorum) was cultured in a Murashige and Skoog (MS) medium at $22{ }^{\circ} \mathrm{C}$ over a $16 \mathrm{~h}$ light $/ 8 \mathrm{~h}$ dark photoperiod in a culture room. Arabidopsis thaliana (Col-0) were used for genetic transformation and were grown over a $16 \mathrm{~h}$ light $/ 8 \mathrm{~h}$ dark light photoperiod at $22{ }^{\circ} \mathrm{C}$.

\subsection{Gene Cloning and Sequence Analysis}

Total RNA was extracted from 'White heaven' leaves using the RNAprep Pure Plant Kit (Tiangen, Beijing, China) according to the manufacturer's instructions. After DNase I (Takara, Bio, Beijing, China) treatment, $1 \mu \mathrm{g}$ of RNA was subject to a reverse transcription reaction using the HiScript Q RT SuperMix Kit (Vazyme, Nanjing, China). The degenerate primers were designed (Supplementary Table S1) and the partial conserved sequence of LlHsfA4 was amplified by homology-based cloning.The full-length sequence of LlHsfA4 was then obtained by $5^{\prime}$ - and $3^{\prime}$ - one step Full Race Kit (Takara, Japan). The conserved domain prediction was carried out using the DNAMAN software and NCBI (https:/ / www.ncbi.nlm.nih.gov/, accessed on 28 August 2021) website. Thephylogenetic tree was analyzed using the ClustalW 2.0 and MEGA 5.0 software.

\subsection{Gene Expression Assay}

The roots, bulbs and leaves of 4-week-old lily plantlets were taken as materials. The RNA of different tissues was extracted and real-time quantitative PCR was used to detect the expression of $L l H s f A 4$. To analyze the response of $L l H s f A 4$ to different abiotic treatments, lily plantlets were exposed to different temperatures $\left(25,28,32,37\right.$ and $\left.42{ }^{\circ} \mathrm{C}\right)$ for $3 \mathrm{~h}$ or to different durations of heat stress $(0,1,3$ and $6 \mathrm{~h})$ at $37^{\circ} \mathrm{C}$, or they were treated with $1 \mathrm{mM} \mathrm{H}_{2} \mathrm{O}_{2}$ for different durations $(0,1,3$ and $6 \mathrm{~h})$. After treatment, the RNA of these leaves was extracted for expression analysis. 18S $r R N A$ was used as a quantification control, which has been validated in previous studies [23]. qRT-PCR analysiswas performed with the $2^{-\Delta \Delta \mathrm{CT}}$ method and primers designed for qPCR analysis are listed in Supplementary Table S1.

To analyze the expression levels of heat-related and ROS-related genes in wild-type and transgenic Arabidopsis plants, the 10-day-old seedlings were collected and the RNA was extracted for real-time quantitative PCR analysis. Each experiment included three biological replicates. All relevant primers are listed in Supplementary Table S1.

\subsection{Promoter Isolation and GUS Activity Assay}

Genomic DNA extraction was carried out using the Genomic DNA Extraction Kit (Tiangen, Beijing, China). The 1800-bp promoter sequence upstream of the ATG of LlHsfA4 was obtained by the hiTAIL-PCR method [56].

For promoter activity research, the DNA of $1800 \mathrm{bp}$ promoter was amplified by PCR and cloned between the PstI and XmaI sites of the pCAMBIA1391 vector, which contains the GUS gene. The $p H s f A 4:: G U S$ vector was obtained and transformed into the Agrobacterium tumefaciens GV3101 strain and the Arabidopsis plants were then infected using the floraldip method [57]. The transgenic seedlings were screened on the MS medium containing $30 \mathrm{mg} / \mathrm{L}$ hygromycin to obtain homozygous transgenic plants for further analysis. 
Histochemical staining for the GUS activity assay in transgenic plants was performed following the methods of He et al. (2012) [58]. 10-day-old seedlings were treated with water (Con), a salt solution $(\mathrm{NaCl}, 150 \mathrm{mM})$, or a mannitol solution $(300 \mathrm{mM})$ for $3 \mathrm{~h}$, or $1 \mathrm{mM}$ $\mathrm{H}_{2} \mathrm{O}_{2}$ for different durations $(0,1,3$ and $6 \mathrm{~h})$ and with heat stress $\left(37^{\circ} \mathrm{C}\right)$ for $3 \mathrm{~h}$ before being subjected to GUS analysis. The treated seedlings were immersed in a staining solution and incubated at $37^{\circ} \mathrm{C}$ for $12 \mathrm{~h}$ and they were then decolorized with $75 \%$ ethanol for $24 \mathrm{~h}$.

\subsection{Subcellular Localization of LlHsfA4}

The ORF of LlHsfA4 was amplified by primers with $\mathrm{XbaI}$ and $\mathrm{KpnI}$ sitesandcloned into a pCAMBIA1300 vector modified with a super promoter and eGFP cDNA to construct pSuper::LlHsfA4-GFP, which was used for subcellular localization, the transient expression of lily leaves and transformation in Arabidopsis.

The binary expression vector $p$ Super::LlHsfA4-GFP was transformed into lily protoplasts and tobacco leaves to examine the subcellular localization of L1HsfA4. GFP images were obtained by a Zeiss LSM510 META confocal microscope with an excitation at $488 \mathrm{~nm}$ and an emission at $525 \mathrm{~nm}$. Protoplast transformation was performed according the Arabidopsis protoplasts transient transform [58]. For tobacco injection, the binary vector was transformed into Agrobacterium GV3101 strains and were injected into Nicotiana benthamiana leaves with nuclear localization marker NF-YA4-mcherry and the silencing suppressor P19 [41] and the treated tobacco seedlings were then put in a chamber with a $16 \mathrm{~h}$ light/8 $\mathrm{h}$ dark light photoperiod at $22{ }^{\circ} \mathrm{C}$. Pictures were obtained after $48 \mathrm{~h}-72 \mathrm{~h}$ [59].

\subsection{Transcriptional Activity Analyses}

The pGBKT7 vector was used for transcriptional activity analysis. Full length (FL) and four short truncated sequences (D1, D2, D3 and D4) of L1HsfA4 were amplified individually using primers with NdeI and BamHI sites and then cloned into pGBKT7to construct pBDLlHsfA4 (FL), pBD-LlHsfA4 (D1), pBD-LlHsfA4 (D2), pBD-LlHsfA4 (D3) andpBD-LlHsfA4 (D4) vectors. The primers used in these experiments are listed in Supplementary Table S1. The vectors of pBD-LlHsfA4 (FL), pBD-LlHsfA4 (D1), pBD-LlHsfA4 (D2), pBD-L1HsfA4 (D3), pBD-LlHsfA4 (D4), pBD-GAL4 (positive control) and pGBKT7 (negative control) were introduced into AH109 yeast cells. Screening was performed on an SD/-Trp medium and an SD/-Trp-His medium and $\beta$-Gal activity was measured via an enzyme assay [23].

\subsection{Thermotolerancetest of Transgenic Arabidopsis}

Recombinant vectors of pSuper::LlHsfA4-GFP were transformed into the Agrobacterium tumefaciens GV3101 strain and infected Arabidopsis plants using the floral-dip method [57]. The transgenic seedlings were then selected on a MS medium containing $30 \mathrm{mg} / \mathrm{L}$ hygromycin to obtain homozygous transgenic plants for a thermotolerance test.

For the thermotolerance assay, LlHsfA4 over expressing plants A4-12 and A4-43 as well as wild-type Arabidopsis were examined. The 5-day-old seedlings were transferred to a $45{ }^{\circ} \mathrm{C}$ environment for $70 \mathrm{~min}$ and then transferred to a $22{ }^{\circ} \mathrm{C}$ normal growth condition for recovery culture. The plant status was observed, photographed and recorded.

\subsection{Transient Expression of Lily Leaves}

The recombinant pSuper::LlHsfA4-GFP vector was transferred into the Agrobacterium tumefaciens strain GV3101, placed in a liquid LB medium overnight, collected by centrifugation, re-suspended in an infiltration buffer $(10 \mathrm{mM} \mathrm{MgCl}, 200 \mathrm{mM}$ acetosyringine and $10 \mathrm{mM}$ MES, pH 5.6) to a final $\mathrm{OD}_{600}$ of about 1.0 and finally, placed in the dark for $3 \mathrm{~h}$. Discs with a $1 \mathrm{~cm}$ diameter from lily leaves were excised using a hole-puncher, infiltrated with an infection solution using a vacuum at $-0.9 \mathrm{M} \mathrm{Pa}$, washed with deionized water, placed on a semi-solid plate ( $0.4 \%$ agar) at room temperature for $48 \mathrm{~h}$ in the dark and then used for DAB staining. 


\subsection{ROS Detecting}

In order to detect the effect of LlHsfA4 on ROS accumulation, DAB and NBT staining were used to detect $\mathrm{H}_{2} \mathrm{O}_{2}$ and $\mathrm{O}_{2}{ }^{-}$accumulation separately. The specific method was as follows: The processed plant materials were placed in a $1 \mathrm{mg} / \mathrm{L} \mathrm{DAB}$ solutionsoaked for $8 \mathrm{~h}$, or in a $1 \mathrm{mg} / \mathrm{L} \mathrm{NBT}$ solution for $15 \mathrm{~min}$ and then placed in $75 \%$ ethanol to decolorize. Photos were then taken for observation purposes [58].

\subsection{Statistical Analysis}

$T$-test analysis of variance was employed to identify treatment means that differed statistically. GraphPad Prism v7.00 was used for all statistical analyses.

\section{Conclusions}

LlHsfA4 can regulate ROS metabolism to enhance basal thermo-tolerance during heat stress response in lilies.

Supplementary Materials: The following are available online at https://www.mdpi.com/article/10 .3390/ijms23010572/s1.

Author Contributions: C.W., Y.Z. and J.H. conceived the study and designed experiments; C.W. and Y.Z. performed main experiments; X.Y. and B.Z. performed subcellular localization and thermotolerance tests of transgenic Arabidopsis; F.X., Y.W. and C.S. prepared materials; J.H. wrote the original draft; M.Y. and N.M. read and provided helpful discussion; X.Z. reviewed and edited the manuscript. All authors have read and agreed to the published version of the manuscript.

Funding: This research was funded by the Natural Science Foundation of Shandong Province, grant number: "ZR2021QC130", the Primary Research \& Development Plan of Shandong Province, China grant number: "2021LZGC019", the National Natural Science Foundation of China, grant numbers "32102427", "31471904" and "31300219" and by the Chinese Universities Scientific Fund, grant numbers "2018QC096" and "2017YY003".

Institutional Review Board Statement: Not applicable.

Informed Consent Statement: Not applicable.

Conflicts of Interest: The authors declare that there is no conflict of interest.

\section{References}

1. Larkindale, J.; Hall, J.D.; Knight, M.R.; Vierling, E. Heat stress phenotypes of Arabidopsis mutants implicate multiple signaling pathways in the acquisition of thermotolerance. Plant Physiol. 2005, 138, 882-897. [CrossRef] [PubMed]

2. Yeh, C.H.; Kaplinsky, N.J.; Hu, C.; Charng, Y.Y. Some like it hot, some like it warm: Phenotyping to explore thermotolerance diversity. Plant Sci. 2012, 195, 10-23. [CrossRef]

3. Gong, Z.; Xiong, L.; Shi, H.; Yang, S.; Herrera-Estrella, L.R.; Xu, G.; Chao, D.-Y.; Li, J.; Wang, P.-Y.; Qin, F.; et al. Plant abiotic stress response and nutrient use efficiency. Sci. China Life Sci. 2020, 63, 635-674. [CrossRef] [PubMed]

4. Konigshofer, H.; Tromballa, H.W.; Loppert, H.G. Early events in signalling high-temperature stress in tobacco BY2 cells involve alterations in membrane fluidity and enhanced hydrogen peroxide production. Plant Cell Environ. 2008, 31, 1771-1780. [CrossRef]

5. Banti, V.; Mafessoni, F.; Loreti, E.; Alpi, A.; Perata, P. The heat-inducible transcription factor HsfA2 enhances anoxia tolerance in Arabidopsis. Plant Physiol. 2010, 152, 1471-1483. [CrossRef] [PubMed]

6. Scharf, K.D.; Berberich, T.; Ebersberger, I.; Nover, L. The plant heat stress transcription factor (Hsf) family: Structure, function and evolution. Biochim. Biophys. Acta 2012, 1819, 104-119. [CrossRef]

7. Nover, L.; Scharf, K.D.; Gagliardi, D.; Vergne, P.; Czarnecka-Verner, E.; Gurley, W.B. The Hsf world: Classification and properties of plant heat stress transcription factors. Cell Stress Chaperones 1996, 1, 215-223. [CrossRef]

8. Nover, L.; Bharti, K.; Doring, P.; Mishra, S.K.; Ganguli, A.; Scharf, K.D. Arabidopsis and the heat stress transcription factor world: How many heat stress transcription factors do we need? Cell Stress Chaperones 2001, 6, 177-189. [CrossRef]

9. Ikeda, M.; Mitsuda, N.; Ohme-Takagi, M. Arabidopsis HsfB1 and HsfB2b Act as Repressors of the Expression of Heat-Inducible Hsfs But Positively Regulate the Acquired Thermotolerance. Plant Physiol. 2011, 157, 1243-1254. [CrossRef]

10. Fragkostefanakis, S.; Simm, S.; El-Shershaby, A.; Hu, Y.J.; Bublak, D.; Mesihovic, A.; Darm, K.; Mishra, S.K.; Tschiersch, B.; Theres, K.; et al. The repressor and co-activator HsfB1 regulates the major heat stress transcription factors in tomato. Plant Cell Environ. 2019, 42, 874-890. [CrossRef] 
11. Bharti, K.; Von Koskull-Doring, P.; Bharti, S.; Kumar, P.; Tintschl-Korbitzer, A.; Treuter, E.; Nover, L. Tomato heat stress transcription factor HsfB1 represents a novel type of general transcription coactivator with a histone-like motif interacting with the plant CREB binding protein ortholog HAC1. Plant Cell 2004, 16, 1521-1535. [CrossRef]

12. Czarnecka-Verner, E.; Pan, S.; Salem, T.; Gurley, W.B. Plant class B HSFs inhibit transcription and exhibit affinity for TFIIB and TBP. Plant Mol. Biol. 2004, 56, 57-75. [CrossRef] [PubMed]

13. Zhuang, L.L.; Cao, W.; Wang, J.; Yu, J.J.; Yang, Z.M.; Huang, B.R. Characterization and Functional Analysis of FaHsfC1b from Festuca arundinacea Conferring Heat Tolerance in Arabidopsis. Int. J. Mol. Sci. 2018, 19, 2702. [CrossRef]

14. Schmidt, R.; Schippers, J.H.M.; Welker, A.; Mieulet, D.; Guiderdoni, E.; Mueller-Roeber, B. Transcription factor OsHsfC1b regulates salt tolerance and development in Oryza sativa ssp japonica. Aob Plants 2012. [CrossRef]

15. Hu, X.J.; Chen, D.; Lynne Mclntyre, C.; Fernanda Dreccer, M.; Zhang, Z.B.; Drenth, J.; Kalaipandian, S.; Chang, H.; Xue, G.P. Heat shock factor $\mathrm{C} 2$ a serves as a proactive mechanism for heat protection in developing grains in wheat via an ABA-mediated regulatory pathway. Plant Cell Environ. 2018, 41, 79-98. [CrossRef] [PubMed]

16. Mishra, S.K.; Tripp, J.; Winkelhaus, S.; Tschiersch, B.; Theres, K.; Nover, L.; Scharf, K.D. In the complex family of heat stress transcription factors, HsfA1 has a unique role as master regulator of thermotolerance in tomato. Genes Dev. 2002, 16, 1555-1567. [CrossRef] [PubMed]

17. Zhu, B.; Ye, C.; Lu, H.; Chen, X.; Chai, G.; Chen, J.; Wang, C. Identification and characterization of a novel heat shock transcription factor gene, GmHsfA1, in soybeans (Glycine max). J. Plant Res. 2006, 119, 247-256. [CrossRef]

18. Liu, H.C.; Liao, H.T.; Charng, Y.Y. The role of class A1 heat shock factors (HSFA1s) in response to heat and other stresses in Arabidopsis. Plant Cell Environ. 2011, 34, 738-751. [CrossRef] [PubMed]

19. Yoshida, T.; Ohama, N.; Nakajima, J.; Kidokoro, S.; Mizoi, J.; Nakashima, K.; Maruyama, K.; Kim, J.M.; Seki, M.; Todaka, D.; et al. Arabidopsis HsfA1 transcription factors function as the main positive regulators in heat shock-responsive gene expression. Mol. Genet.Genom. 2011, 286, 321-332. [CrossRef] [PubMed]

20. Gong, B.; Yi, J.; Wu, J.; Sui, J.; Khan, M.A.; Wu, Z.; Zhong, X.; Seng, S.; He, J.; Yi, M. LlHSFA1, a novel heat stress transcription factor in lily (Lilium longiflorum), can interact with LIHSFA2 and enhance the thermotolerance of transgenic Arabidopsis thaliana. Plant Cell Rep. 2014, 33, 1519-1533. [CrossRef] [PubMed]

21. Schramm, F.; Larkindale, J.; Kiehlmann, E.; Ganguli, A.; Englich, G.; Vierling, E.; von Koskull-Doring, P. A cascade of transcription factor DREB2A and heat stress transcription factor HsfA3 regulates the heat stress response of Arabidopsis. Plant J. 2008, 53, 264-274. [CrossRef]

22. Xin, H.; Zhang, H.; Chen, L.; Li, X.; Lian, Q.; Yuan, X.; Hu, X.; Cao, L.; He, X.; Yi, M. Cloning and characterization of HsfA2 from Lily (Lilium longiflorum). Plant Cell Rep. 2010, 29, 875-885. [CrossRef]

23. Wu, Z.; Liang, J.; Wang, C.; Zhao, X.; Zhong, X.; Cao, X.; Li, G.; He, J.; Yi, M. Overexpression of lily HsfA3s in Arabidopsis confers increased thermotolerance and salt sensitivity via alterations in proline catabolism. J. Exp. Bot. 2018, 69, 2005-2021. [CrossRef]

24. Ohama, N.; Sato, H.; Shinozaki, K.; Yamaguchi-Shinozaki, K. Transcriptional Regulatory Network of Plant Heat Stress Response. Trends Plant Sci. 2017, 22, 53-65. [CrossRef] [PubMed]

25. Baniwal, S.K.; Chan, K.Y.; Scharf, K.D.; Nover, L. Role of heat stress transcription factor HsfA5 as specific repressor of HsfA4. J. Biol. Chem. 2007, 282, 3605-3613. [CrossRef] [PubMed]

26. Von Koskull-Doring, P.; Scharf, K.D.; Nover, L. The diversity of plant heat stress transcription factors. Trends Plant Sci. 2007, 12, 452-457. [CrossRef] [PubMed]

27. Li, F.; Zhang, H.; Zhao, H.; Gao, T.; Song, A.; Jiang, J.; Chen, F.; Chen, S. Chrysanthemum CmHSFA4 gene positively regulates salt stress tolerance in transgenic chrysanthemum. Plant Biotechnol. J. 2018, 16, 1311-1321. [CrossRef] [PubMed]

28. Zhang, H.; Yang, J.; Li, W.; Chen, Y.; Lu, H.; Zhao, S.; Li, D.; Wei, M.; Li, C. PuHSFA4a Enhances Tolerance To Excess Zinc by Regulating Reactive Oxygen Species Production and Root Development in Populus. Plant Physiol. 2019, 180, $2254-2271$. [CrossRef]

29. Chen, S.; Yu, M.; Li, H.; Wang, Y.; Lu, Z.; Zhang, Y.; Liu, M.; Qiao, G.; Wu, L.; Han, X.; et al. SaHsfA4c From Sedum alfredii Hance Enhances Cadmium Tolerance by Regulating ROS-Scavenger Activities and Heat Shock Proteins Expression. Front. Plant Sci. 2020, 11, 142. [CrossRef] [PubMed]

30. Vanderauwera, S.; Suzuki, N.; Miller, G.; van de Cotte, B.; Morsa, S.; Ravanat, J.L.; Hegie, A.; Triantaphylides, C.; Shulaev, V.; van Montagu, M.C.; et al. Extranuclear protection of chromosomal DNA from oxidative stress. Proc. Natl. Acad. Sci. USA 2011, 108, 1711-1716. [CrossRef]

31. Rizhsky, L.; Davletova, S.; Liang, H.; Mittler, R. The zinc finger protein Zat12 is required for cytosolic ascorbate peroxidase 1 expression during oxidative stress in Arabidopsis. J. Biol. Chem. 2004, 279, 11736-11743. [CrossRef]

32. Davletova, S.; Rizhsky, L.; Liang, H.; Shengqiang, Z.; Oliver, D.J.; Coutu, J.; Shulaev, V.; Schlauch, K.; Mittler, R. Cytosolic ascorbate peroxidase 1 is a central component of the reactive oxygen gene network of Arabidopsis. Plant Cell 2005, 17, 268-281. [CrossRef] [PubMed]

33. Fang, Y.; Liao, K.; Du, H.; Xu, Y.; Song, H.; Li, X.; Xiong, L. A stress-responsive NAC transcription factor SNAC3 confers heat and drought tolerance through modulation of reactive oxygen species in rice. J. Exp. Bot. 2015, 66, 6803-6817. [CrossRef] [PubMed]

34. Grassotti, A.; Gimelli, F. BulbandCut Dlower Production in the Genius Lilium: Current Status and the Future. Acta Hortic. 2011, 900, 21-35. [CrossRef] 
35. Zhang, M.-F.; Jiang, L.-M.; Zhang, D.-M.; Jia, G.-X. De novo transcriptome characterization of Lilium 'Sorbonne' and key enzymes related to the flavonoid biosynthesis. Mol. Genet. Genom. 2015, 290, 399-412. [CrossRef]

36. Lazare, S.; Bechar, D.; Fernie, A.R.; Brotman, Y.; Zaccai, M. The proof is in the bulb: Glycerol influences key stages of lily development. Plant J. 2019, 97, 321-340. [CrossRef] [PubMed]

37. Zhang, Q.; Zhang, Y.; Lu, M.H.; Chai, Y.P.; Jiang, Y.Y.; Zhou, Y.; Wang, X.C.; Chen, Q.J. A Novel Ternary Vector System United with Morphogenic Genes Enhances CRISPR/Cas Delivery in Maize. Plant Physiol. 2019, 181, 1441-1448. [CrossRef]

38. Xin, H.B.; Zhang, H.; Zhong, X.H.; Lian, Q.L.; Dong, A.X.; Cao, L.; Yi, M.F.; Cong, R.C. Over-expression of LlHsfA2b, a lily heat shock transcription factor lacking trans-activation activity in yeast, can enhance tolerance to heat and oxidative stress in transgenic Arabidopsis seedlings. Plant Cell Tiss. Org. 2017, 130, 617-629. [CrossRef]

39. Higo, K.; Ugawa, Y.; Iwamoto, M.; Higo, H. PLACE: A database of plant cis-acting regulatory DNA elements. Nucleic Acids Res. 1998, 26, 358-359. [CrossRef]

40. Higo, K.; Ugawa, Y.; Iwamoto, M.; Korenaga, T. Plant cis-acting regulatory DNA elements (PLACE) database: 1999. Nucleic Acids Res. 1999, 27, 297-300. [CrossRef]

41. Liu, J.X.; Howell, S.H. bZIP28 and NF-Y Transcription Factors Are Activated by ER Stress and Assemble into a TranscriptionalComplex to Regulate Stress Response Genes in Arabidopsis. Plant Cell 2010, 22, 782-796. [CrossRef]

42. Kotak, S.; Port, M.; Ganguli, A.; Bicker, F.; von Koskull-Doring, P. Characterization of C-terminal domains of Arabidopsis heat stress transcription factors (Hsfs) and identification of a new signature combination of plant class A Hsfs with AHA and NES motifs essential for activator function and intracellular localization. Plant J. 2004, 39, 98-112. [CrossRef]

43. Yamanouchi, U.; Yano, M.; Lin, H.X.; Ashikari, M.; Yamada, K. A rice spotted leaf gene, SpI7, encodes a heat stress transcription factor protein. Proc. Natl. Acad. Sci. USA 2002, 99, 7530-7535. [CrossRef]

44. Shim, D.; Hwang, J.U.; Lee, J.; Lee, S.; Choi, Y.; An, G.; Martinoia, E.; Lee, Y. Orthologs of the class A4 heat shock transcription factor HsfA4a confer cadmium tolerance in wheat and rice. Plant Cell 2009, 21, 4031-4043. [CrossRef]

45. Andrasi, N.; Rigo, G.; Zsigmond, L.; Perez-Salamo, I.; Papdi, C.; Klement, E.; Pettko-Szandtner, A.; Baba, A.I.; Ayaydin, F.; Dasari, R.; et al. The mitogen-activated protein kinase 4-phosphorylated heat shock factor A4A regulates responses to combined salt and heat stresses. J. Exp. Bot. 2019, 70, 4903-4918. [CrossRef]

46. Li, B.J.; Gao, K.; Ren, H.M.; Tang, W.Q. Molecular mechanisms governing plant responses to high temperatures. J. Integr. Plant Biol. 2018, 60, 757-779. [CrossRef]

47. Perez-Salamo, I.; Papdi, C.; Rigo, G.; Zsigmond, L.; Vilela, B.; Lumbreras, V.; Nagy, I.; Horvath, B.; Domoki, M.; Darula, Z.; et al The heat shock factor A4A confers salt tolerance and is regulated by oxidative stress and the mitogen-activated protein kinases MPK3 and MPK6. Plant Physiol. 2014, 165, 319-334. [CrossRef]

48. Panchuk, I.I.; Volkov, R.A.; Schoffl, F. Heat stress- and heat shock transcription factor-dependent expression and activity of ascorbate peroxidase in Arabidopsis. Plant Physiol. 2002, 129, 838-853. [CrossRef] [PubMed]

49. Tyagi, S.; Verma, P.C.; Singh, K.; Upadhyay, S.K. Molecular characterization of ascorbate peroxidase (APX) and APX-related (APX-R) genes in Triticum aestivum L. Genomics 2020, 112, 4208-4223. [CrossRef] [PubMed]

50. Verma, D.; Upadhyay, S.K.; Singh, K. Characterization of APX and APX-R gene family in Brassica juncea and B. rapa for tolerance against abiotic stresses. Plant Cell Rep. 2021. [CrossRef] [PubMed]

51. Choudhury, F.K.; Rivero, R.M.; Blumwald, E.; Mittler, R. Reactive oxygen species, abiotic stress and stress combination. Plant J. 2017, 90, 856-867. [CrossRef]

52. Kovtun, Y.; Chiu, W.L.; Tena, G.; Sheen, J. Functional analysis of oxidative stress-activated mitogen-activated protein kinase cascade in plants. Proc. Natl. Acad. Sci. USA 2000, 97, 2940-2945. [CrossRef]

53. Ding, H.D.; He, J.; Wu, Y.; Wu, X.X.; Ge, C.L.; Wang, Y.J.; Zhong, S.L.; Peiter, E.; Liang, J.S.; Xu, W.F. The Tomato Mitogen-Activated Protein Kinase SIMPK1 Is as a Negative Regulator of the High-Temperature Stress Response. Plant Physiol. 2018, 177, 633-651. [CrossRef] [PubMed]

54. Gasch, P.; Fundinger, M.; Muller, J.T.; Lee, T.; Bailey-Serres, J.; Mustroph, A. Redundant ERF-VII Transcription Factors Bind to an Evolutionarily Conserved cis-Motif to Regulate Hypoxia-Responsive Gene Expression in Arabidopsis. Plant Cell 2016, 28, 160-180. [CrossRef]

55. Tang, H.; Bi, H.; Liu, B.; Lou, S.L.; Song, Y.; Tong, S.F.; Chen, N.N.; Jiang, Y.Z.; Liu, J.Q.; Liu, H.H. WRKY33 interacts with WRKY12 protein to up-regulate RAP2.2 during submergence induced hypoxia response in Arabidopsis thaliana. New Phytol. 2021, 229, 106-125. [CrossRef] [PubMed]

56. Liu, Y.G.; Chen, Y. High-efficiency thermal asymmetric interlaced PCR for amplification of unknown flanking sequences. Biotechniques 2007, 43, 649-656. [CrossRef] [PubMed]

57. Clough, S.J.; Bent, A.F. Floral dip: A simplified method for Agrobacterium-mediated transformation of Arabidopsis thaliana. Plant J. 1998, 16, 735-743. [CrossRef]

58. He, J.; Duan, Y.; Hua, D.; Fan, G.; Wang, L.; Liu, Y.; Chen, Z.; Han, L.; Qu, L.J.; Gong, Z. DEXH box RNA helicase-mediated mitochondrial reactive oxygen species production in Arabidopsis mediates crosstalk between abscisic acid and auxin signaling. Plant Cell 2012, 24, 1815-1833. [CrossRef] [PubMed]

59. Wang, K.; He, J.; Zhao, Y.; Wu, T.; Zhou, X.; Ding, Y.; Kong, L.; Wang, X.; Wang, Y.; Li, J.; et al. EAR1 Negatively Regulates ABA Signaling by Enhancing 2C Protein Phosphatase Activity. Plant Cell 2018, 30, 815-834. [CrossRef] 